\title{
Why golimumab in the treatment of psoriatic arthritis, ankylosing spondylitis and rheumatoid arthritis?
}

\author{
M. Rossini', O Viapiana ${ }^{1}$, G. Orsolini', E. Fracassi ${ }^{1}$, L. Idolazzi', \\ D. Gatti ${ }^{1}$, S. Adami', M. Govoni ${ }^{2}$ \\ ${ }^{1}$ Rheumatology Unit, University of Verona; \\ ${ }^{2}$ Rheumatology Unit, University of Ferrara
}

\begin{abstract}
SUMMARY
Golimumab is an anti-TNF monoclonal antibody administred subcutaneously once a month and produced with an innovative technology that minimizes immunogenicity. This paper reviews and updates the main studies on the efficacy, safety and pharmacoeconomic aspects of treatment with golimumab of psoriatic arthritis, ankylosing spondylitis and rheumatoid arthritis.
\end{abstract}

Key words: Golimumab, Biologics anti-TNF, Psoriatic arthritis, Ankylosing spondylitis, Rheumatoid arthritis.

Reumatismo, 2014; 66 (4): 285-303

\section{INTRODUCTION}

\section{Unique Features of the Molecule}

Golimumab is a human monoclonal antibody specific for human TNF. It binds to both the soluble and transmenbrane forms of human TNF, giving rise to stable highaffinity complexes and preventing the binding of TNF. Monoclonal antibodies were the first drugs to be produced with modern biotechnology techniques. Laboratory animals are a quick source of antibodies with high affinity and specificity, but the immunogenicity of these molecules can cause rapid clearance, reduced efficacy, and increased risk of infusion reactions in humans. By using new molecular biology techniques, mouse antibodies were reprogrammed in vitro to replace the amino acid residues with corresponding sequences of human origin (1).

Golimumab is a human monoclonal immunoglobulin $\mathrm{G}$ (IgG) $1 \mathrm{k}$ produced by a cell line of murine hydridomas with recombinant DNA technology, using the Medarex UltiMAb $^{\circledR}$ (Medarex, Princeton, NJ, USA) transgenic mouse platform; mice engineered to express human $\operatorname{IgG}$ transgenes are immunized with human recombinant
TNF- $\alpha$ to produce cell lines of hybridomas secreting human monoclonal antibodies that bind to human TNF- $\alpha$ with high affinity $(2,3)$. This technique is able to produce humanized monoclonal antibodies with relatively low immunogenicity and a long half-life in vivo (1).

\section{Pharmacokinetics}

It is the first anti-TNF agent with oncemonthly subcutaneous (SC) administration to have been approved by the U.S. Food and Drug Administration (FDA) and the European Medicines Agency (EMA) for the treatment of of Psoriatic Arthritis (PsA), Ankylosing Spondylitis (AS) and Rheumatoid Arthritis (RA) (4, 5). Golimumab exhibits dose-dependent pharmacokinetics after both intravenous (IV) and SC administration, with a steady-state concentration being reached within 12 weeks. With a single SC administration of $50 \mathrm{mg}$, the mean time to reach maximum serum concentration $(2.5 \mu \mathrm{g} / \mathrm{ml})$ in healthy subjects ranges from 2 to 6 days. Concomitant use of methotrexate with $50 \mathrm{mg}$ SC golimumab increased the mean steady state trough serum concentration to approximately $0.6 \mu \mathrm{g} / \mathrm{ml}$ in patients with RA, 0.5 $\overline{\text { Corresponding author: }}$ Maurizio Rossini, MD Rheumatology Unit University of Verona Policlinico Borgo Roma Piazzale Scuro, 10, 37134 Verona, Italy E-mail: maurizio.rossini@univr.it 
$\mu \mathrm{g} / \mathrm{ml}$ in those with PsA, and $0.8 \mu \mathrm{g} / \mathrm{ml}$ in those with AS, equal to approximately $30 \%$ higher concentrations compared to patients not receiving concomitant methotrexate (6).

A recent randomized open-label phase I study by Zhuang assessed the pharmacokinetics of golimumab after multiple SC (100 mg, $\mathrm{n}=33)$ or IV $(2 \mathrm{mg} / \mathrm{kg}, \mathrm{n}=16)$ administrations every 4 weeks for 20 weeks in 49 adult patients (median age, 57 years) with RA (14). With SC administration, the steady state was reached after approximately 12 weeks with mean trough concentrations ranging from 1.15 to $1.24 \mu \mathrm{g} / \mathrm{ml}$. After the final IV infusion of golimumab $2 \mathrm{mg} / \mathrm{kg}$, the mean clearance was $7.5 \mathrm{ml} / \mathrm{d} /$ $\mathrm{kg}$. The mean terminal half-life after SC and IV administrations was approximately 13 days whereas the absolute bioavailability of the SC formulation was $53 \%$ (7).

The mean volume of distribution of golimumab was $115 \pm 19 \mathrm{ml} / \mathrm{kg}$; this means that the drug was especially present in the circulatory system, with limited extravascular distribution. Population pharmacokinetic analyses carried out on patients with RA also indicated that the concomitant use of methotrexate could reduce the apparent clearance of golimumab by $17.1 \%(6,8)$.

$\mathrm{Xu}$ et al. assessed the impact of SC golimumab on the body weight and immunogenicity of patients with AS (9). The results demonstrated a tendency to greater apparent clearance of the anti-TNF agent with increasing body weight; patients with higher body weight tended to have lower trough serum golimumab concentrations at steady state. Body weight have a significant impact on golimumab clearance: in patients weighing over $100 \mathrm{~kg}$ and not showing adequate clinical response after 3 or 4 doses, one should consider increasing the dose to $100 \mathrm{mg}$ once a month and then, in the event of limited therapeutic benefit after 3 or 4 additional $100 \mathrm{mg}$ doses, whether or not to continue the treatment. When a patient fails to respond to golimumab therapy, one should also consider the possible development of anti-golimumab antibodies (9). Finally, another phase I study did not find any significant racial difference in pharmacoki- netics between two groups of patients of different race (24 Asian and 27 Caucasian) treated with golimumab (10).

\section{Pharmacodynamics}

Golimumab is effective in modulating selective markers of inflammation and bone metabolism. A placebo-controlled doseranging study demonstrated improved levels of CRP and significant reductions compared to baseline in the serum levels interleukin (IL)-6, intercellular adhesion molecules (ICAM)-1, matrix metalloproteinase (MMP)-3, and vascular endothelial growth factor (VEGF); moreover, patients with RA and AS showed a significant reduction in TNF levels and, in patients with PsA, in the levels of IL-8. The variations observed after the initial dose were maintained through week 24 . These changes in biomarkers are consistent with an improvement of the lesions and reduced inflammation and bone remodeling $(11,12)$. A recent study by Kirkham et al. evaluated the effect of golimumab on the lipid profile and inflammatory markers of cardiovascular disease in over 1000 patients with RA enrolled in the GO-BEFORE and GO-FORWARD trials (13). While the serum levels of total and low-density lipoprotein (LDL) cholesterol increased slightly in patients treated with golimumab plus methotrexate, atherogenic indices remained generally stable and favorable changes were observed in LDL subfractions; additionally, the inflammatory markers for cardiovascular disease improved following treatment (13).

\section{CLINICAL EFFICACY}

Several randomized clinical studies have evaluated the efficacy and safety of golimumab in the main rheumatic diseases affecting humans: PsA, AS, and RA (Tab. I).

\section{Psoriatic Arthritis}

The treatment of PsA has radically changed in recent years. In cases of failure of at least one conventional synthetic disease-modifying antirheumatic drug (csDMARD), or in patients with active enthesitis and/or 
Table I - Summary of main phase-III studies on the use of golimumab in psoriatic arthritis (PsA), ankylosing spondylitis (AS) and rheumatoid arthritis (RA).

\begin{tabular}{|c|c|c|c|}
\hline Study & Study design & Number of patients & Target Population \\
\hline $\begin{array}{l}\text { GO-REVEAL } \\
(15-18)\end{array}$ & $\begin{array}{l}\text { Multicenter randomized } \\
\text { placebo-controlled double-blind } \\
\text { phase III trial }\end{array}$ & 405 & $\begin{array}{l}\text { Adult patients with at least a } 6 \text { month history } \\
\text { of moderate/severe active PsA, negative RF } \\
\text { and presence of plaque psoriasis with one } \\
\text { qualifying lesion of at least } 2 \mathrm{~cm} \text { in diameter }\end{array}$ \\
\hline $\begin{array}{l}\text { GO-RAISE } \\
(22-28)\end{array}$ & $\begin{array}{l}\text { International multicenter } \\
\text { randomized placebo-controlled } \\
\text { double-blind phase III study }\end{array}$ & 356 & $\begin{array}{l}\text { Adults patients with active AS despite } \\
\text { current or previous therapy with DMARDs or } \\
\text { NSAIDs for at least } 3 \text { months }\end{array}$ \\
\hline $\begin{array}{l}\text { GO-AFTER } \\
(30-33)\end{array}$ & $\begin{array}{l}\text { Prospective multicenter } \\
\text { randomized placebo-controlled } \\
\text { double-blind phase III trial }\end{array}$ & 461 & $\begin{array}{l}\text { Adult patients with moderate/severe active } \\
\text { RA previously treated with one or more } \\
\text { doses of a biologic anti-TNF without severe } \\
\text { adverse reactions }\end{array}$ \\
\hline $\begin{array}{l}\text { GO-MORE } \\
(34-37)\end{array}$ & $\begin{array}{l}\text { International multicenter } \\
\text { prospective open-label study }\end{array}$ & 3280 & $\begin{array}{l}\text { Patients naive to biologic therapy with active } \\
\text { RA despite DMARD treatment }\end{array}$ \\
\hline $\begin{array}{l}\text { GO-BEFORE } \\
(38-41)\end{array}$ & $\begin{array}{l}52 \text { week randomized } \\
\text { placebo-controlled double-blind } \\
\text { phase III trial }\end{array}$ & 637 & Patients RA with naïve to MTX \\
\hline $\begin{array}{l}\text { GO-FORWARD } \\
(42-45)\end{array}$ & $\begin{array}{l}\text { Multicenter randomized } \\
\text { placebo-controlled double-blind } \\
\text { phase III trial }\end{array}$ & 444 & $\begin{array}{l}\text { Adult patients with moderate/severe active } \\
\text { RA currently treated with MTX and without } \\
\text { previous treatment with other drugs }\end{array}$ \\
\hline
\end{tabular}

dactylitis, or in those with predominantly axial disease not responding to non-steroid anti-inflammatory drugs (NSAIDs), the 2012 EULAR guidelines (14) recommend treatment with a TNF- $\alpha$ inhibitor, preferably with csDMARD. Patients showing inadequate response to a TNF inhibitor may be switched to another drug of the same class (14).

The international, multicenter, randomized, placebo-controlled, double-blind, phase III trial GO-REVEAL (GOlimumaba Randomized EValuation of safety and Efficacy in subjects with psoriatic Arthritis using a human anti-TNF monoclonal antibody) assessed the efficacy and safety of golimumab in patients naïve to biologically derived treatments, affected by active PsA despite therapy with DMARDs or NSAIDs (15-18). The 405 adult patients with a 6 month diagnosis of moderate-to-severe active PsA ( $\geq 3$ swollen joints and $\geq 3$ tender joints), with negative rheumatoid factor and the presence of plaque psoriasis with a qualifying lesion at least $2 \mathrm{~cm}$ in diameter were randomized to one of three groups: $50 \mathrm{mg} / \mathrm{month}(\mathrm{n}=146)$ or $100 \mathrm{mg} / \mathrm{month}$ of SC golimumab $(n=146)$ or SC placebo $(n=113)$. At week 16, patients with less than a $10 \%$ improvement from baseline in the number of swollen and tender joints entered the early escape phase, with golimumab dose escalation (from placebo to 50 $\mathrm{mg}$ or from $50 \mathrm{mg}$ to $100 \mathrm{mg}$ ). The primary endpoint was the percentage of patients with ACR20 response (American College of Rheumatology 20\% improvement criteria) at week 14 . The main secondary endpoints were: proportion of patients with ACR20 response at week 24; PASI75 (Psoriasis Area and Severity Index) response at week 14 in a subset of patients with $\geq 3 \%$ of body surface area involved by psoriasis at baseline; improvement in the NAPSI (Nail Psoriasis Severity Index) score for fingernail lesions, evaluation of dactylitis, enthesitis (MASES, Maastricht Ankylosing Spondylitis Enthesitis Score) and morning stiffness; improvement in HAQ-DI (Health Assessment Questionnaire Disability Index) scores and variations in the scores for the physical component summary (PCS) of the SF-36 (Short-Form 36) questionnaire between baseline and weeks 14 and 24 . The baseline demographic characteristics of patients were well distributed across the treatment groups.

At 14 weeks, $48 \%$ of patients (140 of 292) in the combined golimumab group achieved an ACR20 response compared 
with only $9 \%$ (10 of 113) of those treated with placebo $(\mathrm{P}<0.001)(15)$. Benefit was observed with both the $50 \mathrm{mg}(51 \%)$ and the $100 \mathrm{mg}(45 \%)$ golimumab dose, regardless of methotrexate use; in both cases, the differences were significant compared with placebo (9\%, P<0.001). Similar results were observed at week $24(52 \%, 61 \%$, and $12 \%$, respectively; $\mathrm{P}<0.001)$. More specifically, compared with placebo, significantly more patients receiving golimumab $50 \mathrm{mg}$ showed ACR50 and ACR70 responses both at week $14(30 \%$ and $12 \%$ versus $2 \%$ and $1 \% ; \mathrm{P}<0,001)$ and at week $24(32 \%$ and $19 \%$ versus $4 \%$ and $1 \% ; \mathrm{P}<0.001)(15)$. In the 217 patients $(74 \%)$ with psoriatic lesions involving at least $3 \%$ of the body surface area at baseline, $40 \%$ and $58 \%$ of those treated with golimumab $50 \mathrm{mg}$ and $100 \mathrm{mg}$, respectively, had a PASI75 response at week 14 compared with $3 \%$ of those treated with placebo $(\mathrm{P}<0.001$ for each dose). At week 24, 56\% and $32 \%$ of patients receiving golimumab $50 \mathrm{mg}$ achieved PASI75 and PASI90 responses compared with $1 \%$ and $0 \%$ of those receiving placebo $(\mathrm{P}<0.001)$. Approximately $75 \%$ of patients included in the study had fingernail psoriasis: at weeks 14 and 24, the median percentage change in the NAPSI score for the target fingernail was significantly greater in patients treated with golimumab compared with those receiving placebo $(\mathrm{P}<0.001)(15)$.

The GO-REVEAL study also evaluated two other important parameters of PsA: dactylitis, present at baseline in around one-third of patients, and enthesitis, which affected approximately two-thirds (15). Golimumab treatment significantly improved both enthesitis (number of patients and MASES changes) and morning stiffness at weeks 14 and 24. Finally, patients treated with golimumab showed a significant improvement $(\mathrm{p}<0.001)$ in the HAQ-DI score at 24 weeks and in the physical component of the SF-36 questionnaire at 14 weeks, compared with the placebo group.

The results of the 1 and 2 year follow-up of the GO-REVEAL study were published in $2012(16,17)$. At 24 weeks, patients in the placebo group who did not enter the early escape phase crossed over to golimumab $50 \mathrm{mg}$ : therefore, all patients received treatment with golimumab $50 \mathrm{mg}$ or $100 \mathrm{mg}$ during the follow-up period. The primary endpoint was the change from baseline in the radiographic PsA-modified Sharp/van der Heijde score (SHS) of the hands and feet, as assessed by two independent radiologists, and clinical response during longterm treatment with golimumab.

At 52 weeks, 360 of the 405 initial patients (89\%) were still participating in the study and $358(88 \%)$ continued treatment. At week 24, the mean change from baseline of the PsA-modified SHS indicated significantly less progression in patients receiving golimumab $50 \mathrm{mg}(-0.16, \mathrm{P}=0.011) \mathrm{com}-$ pared with placebo (0.27) (Fig. 1), as did that of the combined golimumab groups $(-0.09, \mathrm{P}=0.015)$, particularly in those receiving golimumab plus methotrexate. The radiographic findings at week 52 showed persistence of radiographic benefit in patients treated with golimumab (Fig. 1), and an improvement in the overall PsA-modified SHS in patients who switched from placebo to active treatment at week 24 .

The clinical efficacy of golimumab observed at week 24 was maintained through week 52 (Fig. 2): ACR20 response in 66\%, $67 \%$, and $71 \%$ of cases; ACR50 response in $39 \%, 49 \%$, and $51 \%$ of cases; ACR70 response in $20 \%, 36 \%$, and $30 \%$ of cases; DAS28-CRP (Disease Activity Score 28 and C-reactive protein) in $81 \%, 82 \%$, and $83 \%$ of cases; PASI75 in $48 \%, 62 \%$ and $69 \%$ of cases initially treated with placebo, golimumab $50 \mathrm{mg}$ and $100 \mathrm{mg}$, respectively.

A subanalysis of these data at 52 weeks focused on two typical symptoms of PsA: enthesitis and dactylitis. At week 52, the improvement seen in patients randomized to receive golimumab $50 \mathrm{mg}$ and golimumab $100 \mathrm{mg}$ was maintained (mean improvements of $54 \%$ for the PsA-modified MASES and $77 \%$ for the dactylitis score). Even the patients with enthesitis/dactylitis at baseline initially randomized to the placebo groups and switched to the active treatment group had a clinically meaningful benefit (39\% improvement in the PsA- 


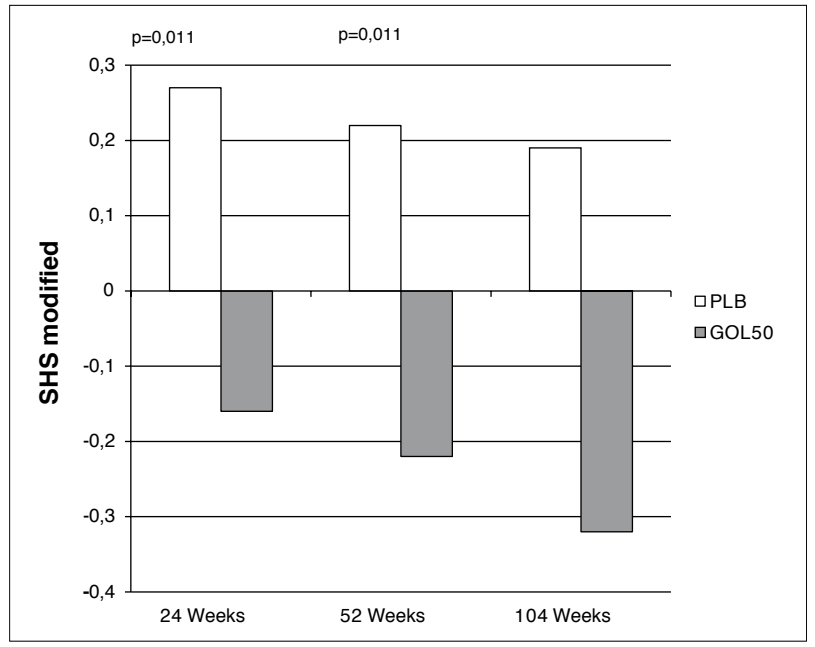

Figure 1 - GO-REVEAL Study. Mean variation from basal of PsA-modified Sharp/van der Heijde score (SHS) radiological index at hands and feet. At week 24 all patients switch to Golimumab $50 \mathrm{mg}$; in the GOL50 group are included patients taking golimumab $50 \mathrm{mg}$ for all study and extension duration and patients that switched to golimumab $100 \mathrm{mg}$ for inadequate response.

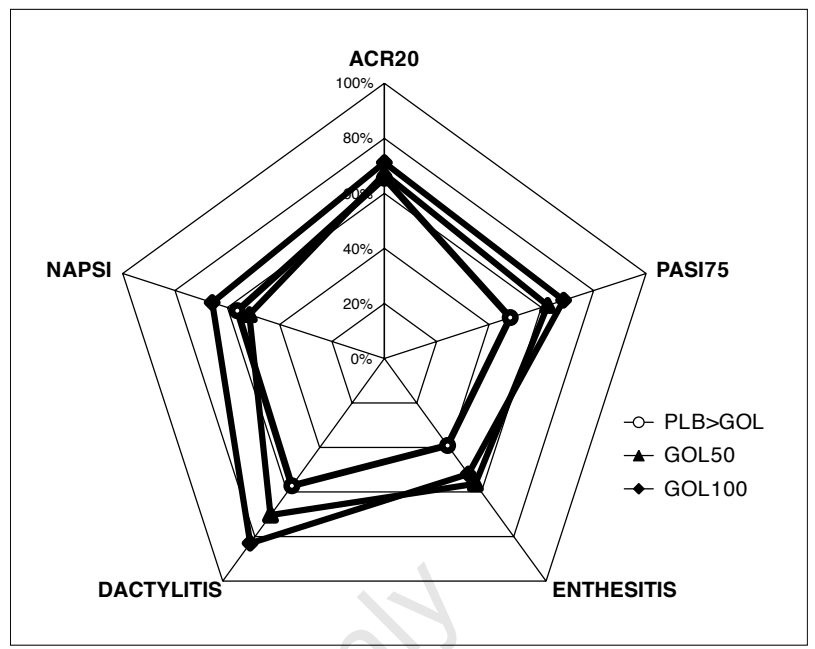

Figure 2 - GO-REVEAL study. Variation at 52 weeks of: ACR20; NAPSI (Nail Psoriasis Severity Index); PASI (Psoriasis Area and Severity Index); PsA-modified MASES (Maastricht Ankylosing Spondylitis Enthesitis Score); Dattilite. All patients in placebo switched to golimumab 50 $\mathrm{mg}$ at week 24. modified MASES, 57\% in the dactylitis score) (16) (Fig. 2).

The same patients were re-evaluated after two years of follow-up (17). Long-term treatment with golimumab is efficacious in maintaining clinical response (ACR20 63\% to $70 \%$, DAS28-CRP $77 \%$ to $86 \%$, PASI75 $56 \%$ to $72 \% ; 67 \%$ to $75 \%$ improvement in dactylitis score; $40 \%$ to $60 \%$ improvement in PsA-modified MASES; $53 \%$ to 59\% improvement in HAQ-DI) and inhibiting radiographic progression of erosions (mean change in the PsA-modified SHS in patients receiving golimumab, -0.36 ), without significant differences between the two drug dosages $(50 \mathrm{mg}$ and $100 \mathrm{mg}$ ). Longterm treatment with golimumab at either dosage (50 mg or $100 \mathrm{mg} / \mathrm{month}$ ) results in a significant and prolonged clinical and radiographic improvement compared with placebo in patients with active PsA (Fig. 1). A recently published analysis investigated correlations between clinical outcome and the reported outcomes of patients enrolled in the GO-REVEAL study (based on questionnaires on physical function, quality of life, mental component and productivity). At 24 weeks, golimumab-treated patients had a significant mean improvement in HAQ-DI (0.36), SF-36 (PCS 7.83, MCS $3.84)$ and productivity score (2.24) compared with the placebo group $(0.01,0.67$ and -0.60 , respectively; $\mathrm{P}<0.001$ for all comparisons). Moreover, a greater proportion of golimumab-treated patients achieved clinically relevant improvements in the HAQ-DI $(\geq 0.30)$ and SF-36 $(\geq 5)$ scores at week $24 \quad(\mathrm{P}<0.05)$ compared with the placebo group; improvements in the DAS28-CRP scores also correlated significantly, albeit moderately, with improvements in HAQ-DI, SF-36 PCS, and productivity. The improvements in these parameters was similar across all groups at the assessments performed at weeks 52 and 104, after the switch from placebo to golimumab (18).

Recently long-term golimumab safety/efficacy in PsA was demonstrated through 5 years (19).

\section{Ankylosing spondylitis}

In 2010, Assessments in Ankylosing Spondylitis International Society (ASAS)/EULAR updated its guidelines for the management of patients affected by AS (20, 
21). The main treatment recommendations about anti-TNF are as follows:

1. anti-TNF agents are recommended in patients with persistently high disease activity despite conventional treatments, without obligatory use of a DMARD before or simultaneously to the anti-TNF agent in patients with axial disease;

2. there is no evidence to support the superior efficacy of any one TNF inhibitor in axial disease and in articular/entheseal disease manifestations; switching to a second TNF inhibitor may be beneficial especially in patients with loss of response;

3. there is no evidence to support the use of biological drugs other than TNF inhibitors.

The international multicenter, randomized, double-blind, placebo-controlled, phase III trial GO-RAISE (GOlimumab-a Randomized Study in Ankylosing Spondylitis Subjects of a Novel anti-TNF mAB Injection [SC] Given Every Four Weeks) evaluated the efficacy and safety of golimumab in 356 adults patients naïve to biologic therapy, with a diagnosis of active AS [BASDAI (Bath Ankylosing Spondylitis Disease Activity Index) $\geq 4$ and a spinal pain score $\geq 4$ on a $0-10$ visual analogue scale (VAS)] despite current or previous therapy with DMARDs or NSAIDs for at least 3 months (22-28). The patients were randomized to one of three groups: $50 \mathrm{mg} / \mathrm{month} \mathrm{SC}$ golimumab $(\mathrm{n}=138), 100 \mathrm{mg} / \mathrm{month} \mathrm{SC}$ golimumab $(n=140)$, or placebo $(n=78)$. The primary endpoint was the proportion of patients with an ASAS20 (ASsessment in AS International Working Group criteria) response at week 14 . Secondary endpoints were an ASAS20 response at week 24, ASAS40 response, the BASDAI for disease activity, VAS score of back pain and night pain, the patient's global assessment, the BASFI (Bath Ankylosing Spondylitis Functional Index) for physical function, the BASMI (Bath Ankylosing Spondylitis Metrology Index) for range of motion, the SF36 Health Survey for quality of life, and the JSEQ (Jenkins Sleep Evaluation Questionnaire) for sleep disturbance. The patients' demographic characteristics were generally well balanced across treatment groups. The primary endpoint was achieved: $59.4 \%$ of patients treated with golimumab $50 \mathrm{mg}$ and $60.0 \%$ of those treated with $100 \mathrm{mg}$ attained an ASAS20 response at week 14 compared with $21.8 \%$ of the placebo group $(\mathrm{P}<0.001)$. Moreover, $43.5 \%, 54.3 \%$, and $15.4 \%$ of patients treated with golimumab $50 \mathrm{mg}$ and $100 \mathrm{mg}$ and with placebo, respectively, achieved an ASAS40 response at week 24 (22) (Fig. 3).

On completion of treatment, the mean BASDAI and BASFI scores were lower in the groups treated with golimumab compared with those who received the placebo. As for the BASMI scores, a significantly greater number of patients treated with golimumab $50 \mathrm{mg}$ and $100 \mathrm{mg}$ showed an improvement from baseline $\geq 1$ unit at week 14 (22). The overall scores for the physical and mental components of the SF-36 improved significantly $(\mathrm{P}<0.05)$ from baseline to weeks 14 and 24 in all golimumabtreated patients. The same patients also showed a significant median improvement from baseline in the JSEQ score at both week 14 and week 24 (both $\mathrm{P}<0.001$ ) (23). Wagner et al. attempted to identify the serum biomarkers modulated by golimumab treatment and associated with a clinical response in 100 patients with AS enrolled in the GO-RAISE trial (24). Golimumab treatment significantly reduced many serum proteins, including acute phase reactants (CRP, haptoglobin, amyloid P), complement markers (complement 3), hematological factors (ferritin), inflammatory markers (Chemokine ligand 5, Epithelial neutrophil-activating protein 78, ICAM1 , macrophage anti-inflammatory protein 1 $\beta$, MMP-3, TIMP-1, TNF receptor II), metabolic markers (plasminogen activator inhibitor-1) and other markers (thyroxinbinding globulin, sex hormone-binding globulin, VEGF), at both 4 and 14 weeks compared with placebo. Logistic regression analysis showed that the association of 2 or 3 biomarkers (insulin, leptin, immunoglobulin M, VEGF) was more predictive of clinical outcome compared with $\mathrm{C}$ reactive protein $(\mathrm{CPR})$ alone. Golimumab 


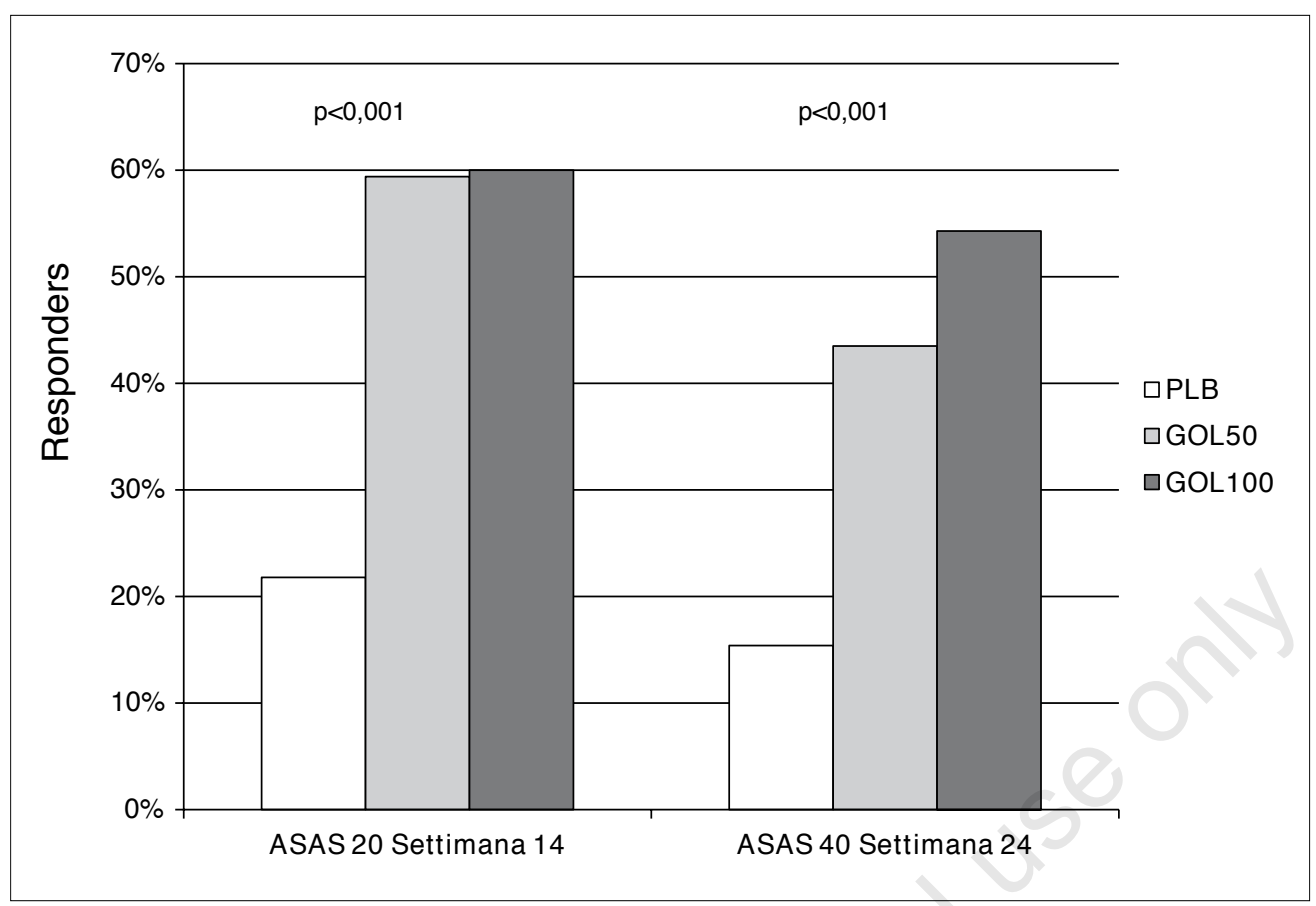

Figure 3 - Go-RAISE study. ASAS, Assessment in AS International Working Group criteria 20 and 40 , at week 14 and 24.

is able to modulate acute-phase reactants and inflammatory markers in patients with AS (24).

Braun et al. published the results of the long-term follow-up (104 weeks) of the GO-RAISE trial (25). At week 104, $38.5 \%, 60.1 \%$, and $71.4 \%$ of the patients initially treated with placebo, golimumab $50 \mathrm{mg}$ and $100 \mathrm{mg}$, respectively, showed an ASAS20 response; $38.5 \%, 55.8 \%$, and $54.3 \%$ an ASAS40 response, and $21.8 \%$, $31.9 \%$, and $30.7 \%$ were in ASAS partial remission. Additionally, the mean BASDAI and BASFI scores were lower than 3 in all treatment groups.

The 4 and 5 year updates of the GO-RAISE trial confirm the findings observed at year $2(26,27)$. In particular, the assessment at year 4 considered the radiographic progression of disease (26). At week 208, after treatment with golimumab for 3.5 to 4 years, the change (mean $\pm \mathrm{SE})$ in the modified Stoke AS Spine Score (mSASSS) was $2.1 \pm 5.2$ in the patients switched from placebo to golimumab, and $1.3 \pm 4.1$ and $2.0 \pm 5.6$ in those treated with golimumab $50 \mathrm{mg}$ and $100 \mathrm{mg}$, respectively. Less than one-third of patients had a definitive change compared to the baseline mSASSS (>2). At week 208, less radiographic progression was noted in patients without syndesmophytes at baseline $(0.2$ versus 2.8 in patients with $\geq 1$ syndesmophytes; $\mathrm{P}<0.0001)$ and lower baseline CPR (0.9 versus 2.9 with CRP $\leq 1.5 \mathrm{mg} / \mathrm{dl}$ and $>1.5 \mathrm{mg} / \mathrm{dl}$, respectively; $\mathrm{P}=0.0004)$. Radiographic progression remained stable at the assessments at year 2 and 4, suggesting no acceleration of new bone formation over time (26).

Of the 356 patients included in the study, 254 continued treatment through week 52 ( 5 years). The reduction in signs and symptoms of AS and the improvement in physical function and range of motion seen at week 14 were maintained to year 5 (27).

Finally, Braun also investigated the effect of golimumab on spinal inflammation seen on magnetic resonance imaging (MRI) in a subset of 98 AS patients of the GO-RAISE trial who underwent complete serial MRI (baseline, week 14 and week 104) (28). The MRI images were read by two independent radiologists using the SA spine MRI-activity (ASspiMRI-a) score. The 
baseline ASspiMRI-a scores were lower in the group treated with golimumab 100 mg (3.5) compared with those in the placebo group (6.8) and the golimumab 50 mg group (7.8). After adjustment for disparities in the baseline ASspiMRI-a scores, the improvement versus placebo became significant both for the $50 \mathrm{mg}(\mathrm{P}=0.011)$ and for the $100 \mathrm{mg}(\mathrm{P}=0.002)$ golimumab groups. The improvements in the ASspiMRI-a score after 14 weeks of golimumab therapy were maintained to week 104 and correlated only with the disease activity score (ASDAS) and CRP, but not with the other clinical outcomes (28).

\section{Rheumatoid arthritis}

The guidelines of the European League Against Rheumatism (EULAR) on the management of RA have established that (29):

1. when poor prognostic factors are present, addition of a biological DMARD (bDMARD) should be considered;

2. in patients responding insufficiently to methotrexate and/or other csDMARD strategies, with or without glucocorticoids, bDMARDs (TNF inhibitors, abatacept or tocilizumab, and, under certain circumstances, rituximab) should be commenced with methotrexate;
3. if a first bDMARD has failed, patients should be treated with another bDMARD; if a first TNF inhibitor therapy has failed, patients may receive another TNF inhibitor or a biological agent with another mode of action.

The efficacy of golimumab has been evaluated in different subsets of RA patients (Fig. 4).

The prospective, multicenter, international, randomized, double-blind, placebo-controlled, phase III trial GO-AFTER (GOlimumab After Former anti-TNF Therapy Evaluated in Rheumatoid Arthritis) investigated the efficacy and safety of golimumab in patients with active RA who had been treated with at least one TNF inhibitor (3032). The study population consisted of 461 adult patients with moderate-to-severe active RA, who had received (at least 8 to 12 weeks prior to administration of the study drug) one or more doses of a biological anti-TNF agent (infliximab, etanercept, and/or adalimumab) without reporting severe adverse reactions. The patients had discontinued the anti-TNF $\alpha$ agent because of ineffectiveness ( $n=269,58 \%$ of patients) or intolerance and poor accessibility of the $\operatorname{drug}(n=246,53 \%$ of patients). The patients were randomized to three study arms: 50

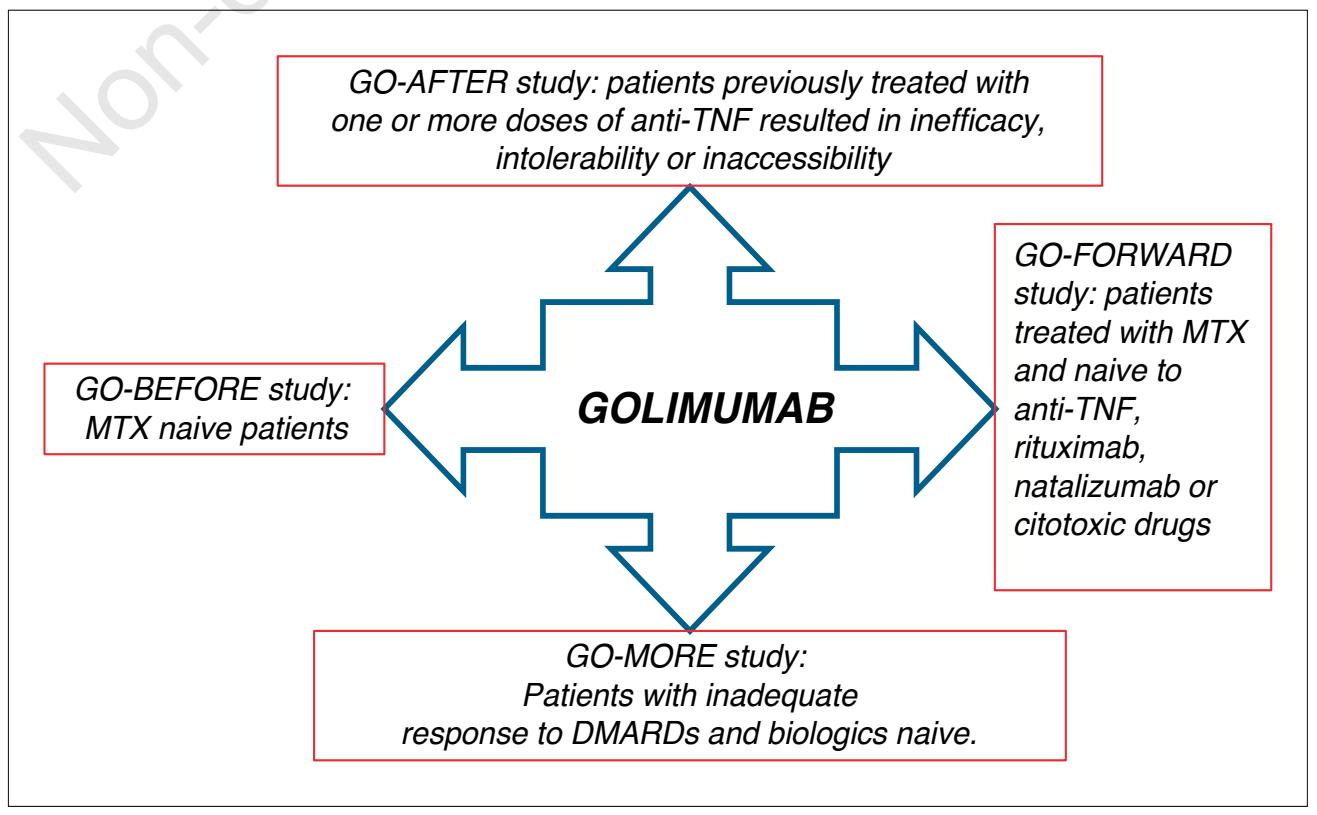

Figure 4 - Different subsets of RA patients investigated in trials on golimumab efficacy. 
$\mathrm{mg} / \mathrm{month}$ of SC golimumab ( $\mathrm{n}=153), 100$ $\mathrm{mg} / \mathrm{month}$ of SC golimumab $(\mathrm{n}=153)$ or SC placebo $(n=155)$. At week 16 , patients who had less than a $20 \%$ improvement in symptoms were switched from placebo to $50 \mathrm{mg}$ golimumab, or from $50 \mathrm{mg}$ to 100 $\mathrm{mg}$ golimumab. The primary endpoint was the proportion of patients with an ACR20 response at week 14, whereas the main secondary endpoints were ACR20 response at week 24, ACR50 and ARC70 responses at weeks 14 and 24, DAS28 (CRP) response at weeks 14 and 24, and improvement in the HAQ-DI score and fatigue [assessed with the Functional Assessment of Chronic Illness Therapy - Fatigue (FACIT-F) questionnaire] at weeks 14 and 24.

The analysis of the primary endpoint at week 14 showed that significantly more patients treated with golimumab achieved an ACR20 response compared with the placebo group (Fig. 5).

More specifically, $35 \%$ of patients treated with golimumab $50 \mathrm{mg}$ achieved the primary endpoint of ACR20 response at week 14 compared with $18 \%$ of patients receiving placebo $(\mathrm{P}=0.0006)$. A similar situation was seen at week 24 (Fig. 5): $34 \%$ of patients receiving golimumab $50 \mathrm{mg}$ attained an ACR20 response compared with $17 \%$ of those treated with placebo $(\mathrm{P}=0.0005)$. The proportions of patients achieving ACR50 and ACR70 responses were also significantly higher among the golimumab-treated groups, both at weeks 14 and 24 . The difference between the percentage of patients achieving an ACR20 response after receiving golimumab or placebo was greater when a concomitant DMARD was associated. Significantly more patients treated with golimumab achieved an ACR20 response than did those on placebo, even when the subject had received prior treatment with one or two anti-TNF agents, and the response was independent of the reason for discontinuation of the anti-TNF (ineffectiveness or intolerance). Finally, the difference between the combined golimumab groups and the placebo group was significant as of the first administration of the drug. At weeks 14 and 24, significantly more patients treated with golimumab achieved a DAS28 (EULAR) response and a DAS28 (ESR) remission compared to those receiving placebo. In particular, at week 14 , administration of golimumab $50 \mathrm{mg}$ resulted in a better DAS28 response and DAS28 remission compared with placebo $(49 \%$ versus $27 \% ; \mathrm{P}=0.0001 ; 8 \%$ versus $1 \%, \mathrm{P}=0.0009)$. At week 24 , similar results were observed for DAS28 response and DAS28 remission. Finally, at week 24, only $34 \%(n=53)$ of patients treated with placebo had a minimum clinically relevant reduction in HAQ-DI, compared with 50\% $(\mathrm{n}=77)$ of those receiving golimumab 50 $\mathrm{mg}(\mathrm{P}=0.0044)$ and $54 \%(\mathrm{n}=82)$ of those receiving $100 \mathrm{mg}(\mathrm{P}=0.0006)$. The improvement from baseline to weeks 14 and 24 in FACIT-F was significantly greater for golimumab than for placebo (30).

An important aspect of the management of RA cases that are difficult to treat concerns maintaining the response over time. Smolen's group recently published the results of the long-term extension (160 weeks) of the GO-AFTER trial (31). After week 24 , the patients receiving placebo crossed over to golimumab $50 \mathrm{mg}$, whereas those

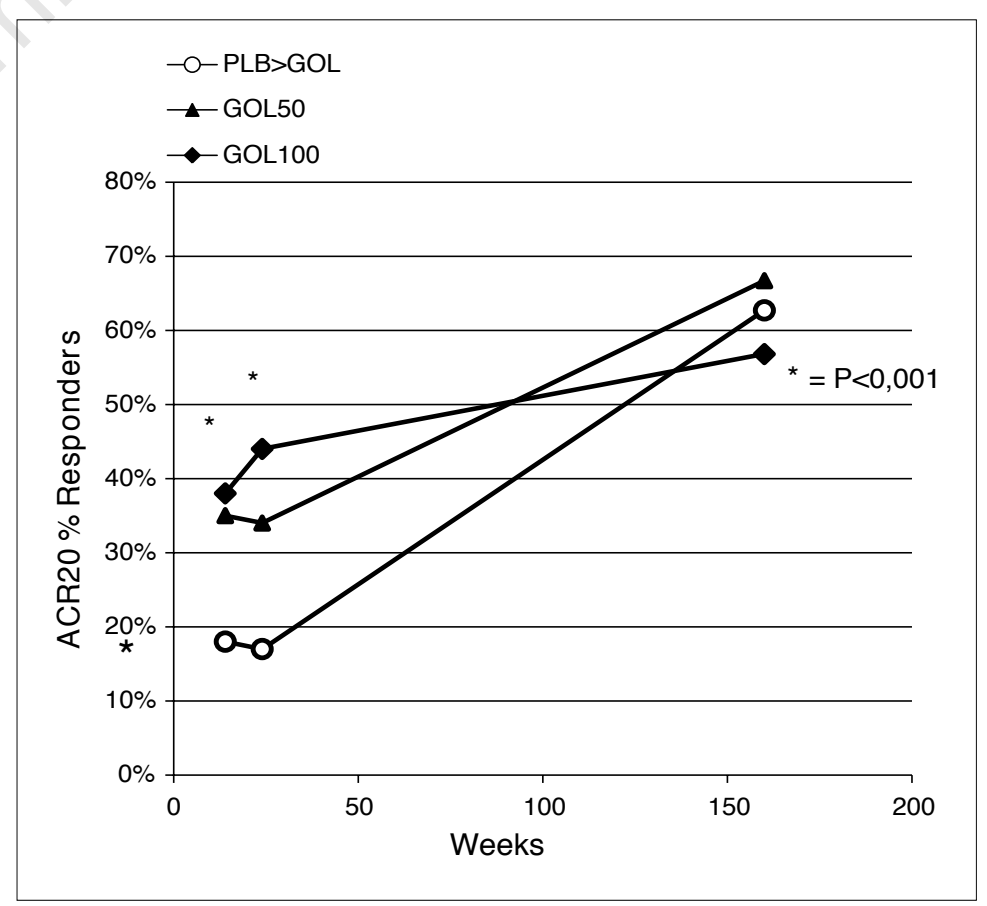

Figure 5 - GO-AFTER. ACR20 response at week 14, 24 and 160. All patients in placebo switched to Golimumab $50 \mathrm{mg}$ at week 24 . 
receiving $50 \mathrm{mg}$ could either continue with this dose or switch to golimumab $100 \mathrm{mg}$. A total of 236 patients $(51 \%)$ continued treatment until week 160. From week 24 to week 100, the ACR20, DAS28 and HAQDI responses were maintained in $70 \%$ to $73 \%, 78 \%$ to $84 \%$, and $75 \%$ to $81 \%$ of responders, respectively. At week 160, an ACR20 response was observed in $63 \%$ of patients initially treated with placebo, in $67 \%$ of those treated with golimumab 50 $\mathrm{mg}$, and in $57 \%$ of those treated with golimumab $100 \mathrm{mg}$ (Fig. 5); improvements in the HAQ-DI score were seen in 59\%, 65\%, and $64 \%$ of cases, respectively. Moreover, the addition or dose escalation of golimumab enhanced the clinical response.

In patients with active RA previously treated with an anti-TNF agent, prolonged use of golimumab 50 and $100 \mathrm{mg} / \mathrm{month}$ enabled the improvement in signs/symptoms and physical function to be maintained in approximately $57 \%$ to $67 \%$ of patients who continued the treatment (30). The 5 year results of the 183 patients who continued treatment through week 252 in the GO-AFTER trial were recently presented at the EULAR 2013 conference (32). The analysis of the patients with available data showed an ACR20 response in $60.3 \%$ of cases, an ACR50 response in $42.3 \%$, an ACR70 response in $21.7 \%$, and a DAS28CRP EULAR response in $84.3 \%$; moreover, $29.0 \%$ of patients had a DAS28-CRP $<2.6$ and $16.0 \%$ a Clinical Disease Activity Index $(\mathrm{CDAI}) \leq 2.8$. The efficacy of golimumab was maintained to 5 years in patients with refractory RA who continued treatment, and its long-term safety is consistent with that of other anti-TNF- $\alpha$ agents (32). Recently, new insights into the efficacy of golimumab plus methotrexate in patients with active rheumatoid arthritis who discontinued prior anti-tumour necrosis factor therapy were reported by post-hoc analyses from the GO-AFTER study (33). Patients with active RA previously treated with $\geq 1$ TNF inhibitor had clinically relevant improvement with golimumab+MTX, which appeared somewhat enhanced among those who received only etanercept or infliximab as their prior TNF inhibitor. The prospective, international (40 participating countries), multicenter (475 centers), openlabel trial GO-MORE investigated the efficacy of SC or IV golimumab as an add-on to a DMARD in adult patients ( $\geq 18$ years) naïve to biological drugs and affected by RA that was inadequately controlled by the DMARD (DAS28-ESR 23.2) (34-37).

In part 1 of the study, the patients were treated with golimumab $50 \mathrm{mg}$ SC (delivered via an automatic injector) once a month for 6 months. The primary end-point was a good/moderate EULAR response (DAS28-ESR) after 6 months of treatment; moreover the study also evaluated whether the response to golimumab could be influenced by variables such as methotrexate dosage, concomitant DMARD, steroid use or the number of failed DMARDs.

In part 2, patients with a good or moderate response but not in remission (DAS28ESR <2.6) at 6 months were randomly allocated to one of two groups: golimumab $50 \mathrm{mg}$ SC once monthly or combined IV and SC golimumab, with assessment of DAS28-ESR remission at 12 months. The primary endpoint of part 2 of the study was remission at the beginning of month 11 and the end of month 12 (34). A total of 3366 patients were enrolled; $91.7 \%$ of them completed part 1 of the study. At 6 months, $82.1 \%$ of the 3280 patients included in part 1 (83\% women; mean age, 52.3 years; mean disease duration, 7.6 years; mean DAS28-ESR, 5.97; concomitant methotrexate, $81 \%$; all with prior DMARD therapy) showed a good (36\%) or moderate $(46.1 \%)$ DAS28-ESR response, achieved after only 2 months of treatment. Analysis of the EULAR responses by the number of previous failed DMARDs or other concomitant variables (methotrexate dose, DMARD type or corticosteroid use) did not show statistically significant differences: approximately $80 \%$ of patients in all subgroups had a good/moderate EULAR response (34). The rates of good-to-moderate EULAR response, low DAS-ESR disease activity, and remission increased steadily during the treatment period; at 6 months, $23.9 \%$ of patients also achieved disease remission. Even the HAQ-DI scores im- 
proved after golimumab treatment: either no functional change or only a minimal change (HAQ-DI $\leq 0.5$ ) was attained in $37.4 \%$ of cases after 6 months. The patients with short duration of disease were more likely to achieve remission: $27.8 \%$ for disease duration less than 2 years versus $21 \%$ if more than 10 years. In conclusion, the addition of golimumab proved to be effective in treating active RA despite DMARD treatment. In part 2 of the study, 490 patients not in remission could be assessed for efficacy: at 12 months the two $\mathrm{SC}$ and IV+SC treatments resulted in similar DAS28-ESR remission rates. The mean normalized AUC (area under the curve) for DAS28-ESR from month 6 through 12 was similar in the two groups: 3.67 in the group treated with $\mathrm{IV}+\mathrm{SC}$ golimumab and 3.67 in the group receiving only $\mathrm{SC}$ golimumab $(\mathrm{P}=0.931)$. Combination of the two golimumab formulations failed to yield any additional benefit compared to the SC formulation alone (34). Finally, add-on golimumab in this population of patients with active RA despite DMARD therapy allowed for a good Comprehensive Disease Control (combined endpoint of clinical remission, low disease activity and important patient outcomes such as physical function and pain reduction) (35).

At the recent EULAR 2013 conference further analyses of the GO-MORE trial were presented (34). Wollenhaupt et al. evaluated the efficacy and safety of golimumab added to either methotrexate $(81.2 \%)$ or leflunomide $(9.3 \%)$. After 6 months the results were similar; the percentage of EULAR response was $85 \%$ for the combination with methotrexate and $81 \%$ for the combination with leflunomide (36).

Analyzing the patients' baseline characteristics and the clinical efficacy according to the geographic region in which the GOMORE trial was conducted, Durez found considerable variations in these parameters (37). Firstly, a high EULAR disease activity at baseline was predominant in South Africa, Asia, and Latin America, whereas disease duration was longer in Latin America and South Africa. As a consequence, the remission rates varied considerably depending on the geographic region, with the lower remission rates being generally observed in the regions with higher disease activity at baseline and longer disease duration (37).

The 52 week, randomized, placebo-controlled, double-blind, phase III trial GOBEFORE (Golimumab Before Employing Methotrexate as the First-Line Option in the Treatment of Rheumatoid Arthritis of Early Onset), followed by a 5 year extension, evaluated 637 RA patients naïve to methotrexate, randomly allocated to one of 4 groups: placebo plus methotrexate, golimumab $100 \mathrm{mg}$ plus placebo, golimumab $50 \mathrm{mg}$ plus methotrexate, or golimumab $100 \mathrm{mg}$ plus methotrexate. The primary endpoint was the difference in ACR50 response at week 24 between groups 3 and 4 combined versus group 1 and a pairwise comparison between group 3 or group 4 versus group $1(38,39)$.

Intention-to-treat (ITT) analysis of the ACR50 response at week 24 did not show any significant difference between the combined group and group 1 (38.4\% versus $29.4 \%$; $\mathrm{P}=0.053$ ), whereas a modified post-hoc ITT analysis (which excluded three patients who were not treated) revealed statistically significant differences between the combined group and placebo plus methotrexate group $(38.5 \%$ versus 29.4\%; $\mathrm{P}=0.049$ ) and between $50 \mathrm{mg}$ plus methotrexate group (40.5\%; $\mathrm{P}=0.038)$, but not $100 \mathrm{mg}$ plus methotrexate group (36.5\%; $\mathrm{P}=0.177)$ and placebo plus methotrexate group (Fig. 6).

The combination of golimumab and methotrexate allowed for significantly better results than those observed with placebo plus methotrexate in most of the other measures of efficacy, including DAS28 response/remission (38).

Recently, a post hoc analysis of methotrexate-naïve RA patients in the GO-BEFORE was reported (40). Clinical response was greater in the golimumab + methotrexate groups vs. placebo + methotrexate for all of the outcomes evaluated. Furthermore, the treatment effect of golimumab + methotrexate was consistenly greater among patients in the severe disease subsets 


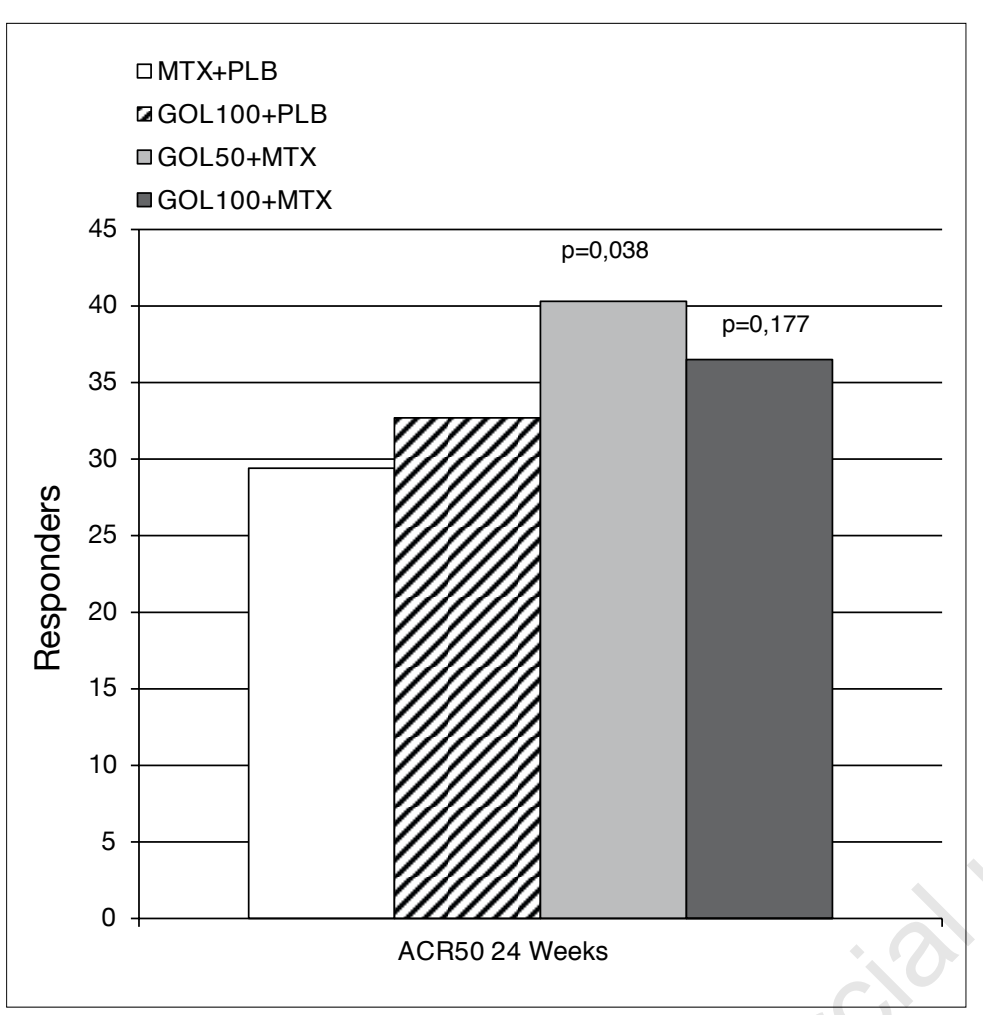

Figure 6 - GO-BEFORE study. ACR50 response at 24 weeks. Modified post-hoc ITT analysis.

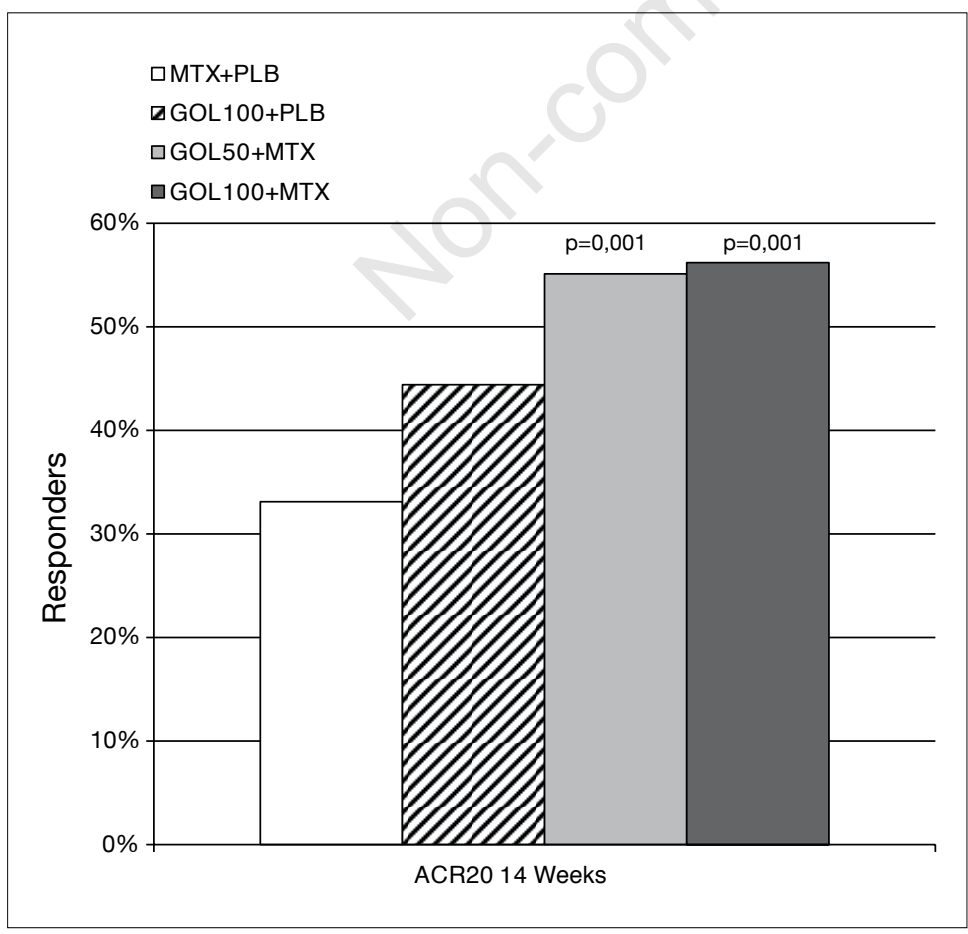

Figure 7 - GO-FORWARD study. ACR20 response at week 14. when compared with all the overall GOBEFORE trial population. The treatment benefit of golimumab + methotrexate vs methotrexate monotherapy was most pronounced within the subsets of patients with $\mathrm{CRP} \geq 3.0 \mathrm{mg} / \mathrm{dL}$ and $\mathrm{SJC} \geq 20 / \mathrm{TJC} \geq 12$.

After completing the 52 weeks of therapy, the patients treated with placebo plus methotrexate could switch to golimumab $50 \mathrm{mg}$ plus methotrexate, methotrexate and corticosteroid use could be adjusted, and a single change in golimumab dose (from 50 to $100 \mathrm{mg}$ or from 100 to $50 \mathrm{mg}$ ) was permitted. The 5 year follow-up was completed by $402(66.1 \%)$. At week 256, $84.3 \%$ of patients had an ACR20 response, $93.9 \%$ a EULAR DAS28-CRP response and 80.6\% $\mathrm{a} \geq 0.25$ improvement in the HAQ-DI (39). About the effects on bone involvement in RA, golimumab, in combination with methotrexate, has shown to inhibit radiological progression of erosions more than methotrexate alone (41) (Fig. 7), and after 5 years among the patients treated with golimumab plus methotrexate $64 \%$ did not show radiographic progression (39).

The multicenter, randomized, placebo-controlled, double-blind, phase III trial GOFORWARD (GOlimumab FOR subjects With Active RA Despite methotrexate) aimed at evaluating the efficacy and safety of golimumab in adult patients with active moderate/severe RA treated with methotrexate ( $\geq 15 \mathrm{mg} /$ weekly) and naïve to antiTNF, rituximab, tocilizumab os cytotoxic agents (42-45).

The 444 patients were enrolled in 4 groups: placebo plus methotrexate (group $1, \mathrm{n}=133$ ), golimumab $100 \mathrm{mg} / \mathrm{month}$ plus placebo (group 2, n=133), golimumab SC $50 \mathrm{mg} / \mathrm{month}$ plus methotrexate (group $3, \mathrm{n}=89$ ) and golimumab $100 \mathrm{mg} / \mathrm{month}$ plus methotrexate (group 4, $n=89$ ). Coprimary endpoints were the proportion of patients with an ACR20 response at week 14 and the improvement from baseline in the HAQ-DI score at week 24. The main secondary endpoints were DAS28 (CRP) response at week 14, ACR20 response at week 24 and the improvement from baseline in the HAQ-DI score at week 14. At week 14 , a significantly higher proportion 
of patients treated with $50 \mathrm{mg}(55.1 \%)$ and $100 \mathrm{mg}(56.2 \%)$ golimumab plus methotrexate achieved an ACR20 response compared with the placebo group (33.1\%; $\mathrm{P}=0.001$ ) (Fig. 8). Moreover, at week 24 the median improvement in the HAQ-DI score was significantly greater among patients treated with golimumab plus methotrexate $(-0.44)$ compared with those treated golimumab or methotrexate used as a monotherapy $(-0.13, \mathrm{P}<0.001)$. As for the secondary endpoints, the percentages of patients with an ACR50 and ACR70 response at week 14 and ACR20, ACR50 and ACR70 at week 24 were significantly higher for patients treated with golimumab plus methotrexate compared with placebo plus methotrexate ( $\mathrm{P}<0.05$ for all comparisons) (42). The result of the 52 week follow-up of the GO-FORWARD trial showed an ACR20 improvement of $44 \%$ in group $1,45 \%$ in group 2, 64\% in group 3, and 58\% in group 4 . These results demonstrate that the response rates achieved with golimumab at week 24 are maintained to 52 (43).

Recently, Keystone et al. also published the results at 104 weeks of the GO-FORWARD trial (44). The clinical improvement was maintained through week $104 ; 74.7 \%$ and $71.6 \%$ of patients treated with golimumab $50 \mathrm{mg}$ and $100 \mathrm{mg}$, respectively, attained an ACR20 response. The majority (105/129; $88 \%$ ) of patients treated with golimumab plus methotrexate who had an improvement in the HAQ-DI score $\geq 0.25$ at week 24 maintained this beneficial effect on physical function up to week 104. Patients with delayed golimumab treatment showed greater radiographic progression at week 104 (mean change score $=1.15$ ) compared to those with early treatment with golimumab plus methotrexate (0.52) (44).

A total of 313 patients continued treatment through week 252 (5 years) and 301 completed the safety follow-up through week 268. After 5 years of treatment, $76.0 \%$ of all patients had an ACR20 response, $89.5 \%$ a DAS28-CRP EULAR response, and $68.5 \%$ an improvement in the HAQ-DI $\geq 0.25$. The percentage of patients retained in the study was high $(70.5 \%)$, with long-term maintenance of improvement in RA symptoms/

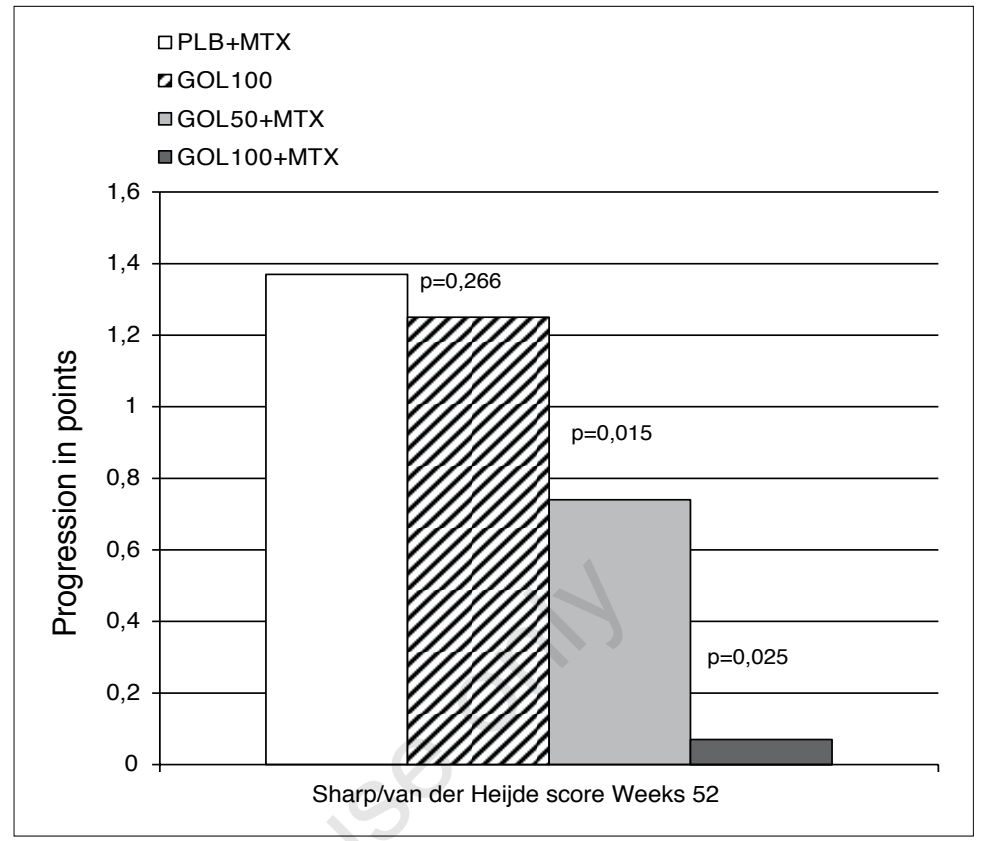

Figure 8 - Effects of Golimumab on radiographic progression measured with SHS (Sharp/van der Heijde score) in the GO-BEFORE study.

signs and physical function after treatment with golimumab plus metotrexate (45).

\section{TOLERABILITY}

Golimumab was generally well tolerated, with a safety profile consistent with that of other anti-TNF agents.

In PsA patients of the GO- REVEAL study the most frequent adverse reactions were nasopharyngitis and upper respiratory tract infection (especially dosage) with the 100 mg (15). Risk of side effects seems to be unchanged by treatment duration: after 52 weeks types and frequency of such events were similar to week 24 (16). No new adverse events were recorded in the two years of follow-up nor any cases of active tuberculosis. The long-term safety profile of golimumab is consistent with that of the other anti-TNF agents used to treat this disease (17).

In AS, At week 16, $77.3 \%$ of patients receiving golimumab and $74.0 \%$ of those receiving placebo had had $\geq 1$ adverse event, with similar proportions in the two golimumab groups $(50 \mathrm{mg}, 79.0 \% ; 100 \mathrm{mg}$, 
$75.7 \%$ ). On completion of the study (week 24 ), these percentages were $85.6 \%$ and $79.9 \%$, respectively (22). Golimumab safety at week 104 was similar to that observed at week 24 and consistent with that of other anti-TNF agents (24). After 5 years of AS treatment severe adverse events were reported by $17.1 \%$ of patients receiving 50 $\mathrm{mg}$ golimumab and $22.0 \%$ of all patients receiving golimumab (27).

In RA patients at week 16 of GO-AFTER study, adverse events were reported in $70 \%$ of patients receiving placebo, $61 \%$ of those treated with golimumab $50 \mathrm{mg}$ and $74 \%$ of those treated with golimumab $100 \mathrm{mg}$, whereas the percentages of severe adverse events were $7 \%, 3 \%$, and $5 \%$, respectively (30). At week 160 , the incidences of adverse events per 100 patient-years in subjects treated with golimumab $50 \mathrm{mg}$ and $100 \mathrm{mg}$ were 4.70 and 8.07 for severe infections, 0.95 and 2.04 for malignancy, and 0.00 and 0.62 for death, respectively (31).

After 5 years the most common adverse events were upper respiratory tract infections $(27.1 \%)$, sinusitis $(17.1 \%)$, and nasopharyngitis $(16.9 \%)$, with a long-term tolerability similar to the other anti-TNF $\alpha$ agents (32). In the first 6 months among patients in the GO-MORE study the most common treatment-related adverse events observed were nasopharyngitis $(4.8 \%)$, urinary tract infections $(3.3 \%)$, headache $(3.2 \%)$, diarrhea $(2.7 \%)$, and bronchitis $(2.4 \%)$.

The overall incidence of these effects in the following 6 months was similar in all treatment groups, independently from golimumab preparation type (34). Among GOBEFORE study RA patients the most frequent adverse events in the groups treated with golimumab plus methotrexate were nausea, upper respiratory tract infection, increased hepatic transaminases, dyspepsia, and headache (36). After 5 years the most common adverse events were upper airway infections (29.4\%), nausea (19.6\%), bronchitis $(16.6 \%)$, and increased alanine aminotransferase (16.1\%) (38). In the GOFORWARD study at week 16 , the proportion of patients with adverse events was
$60.9 \%$ in group 1 (placebo+methotrexate), $63.2 \%$ in group 2 (golimumab $100 \mathrm{mg} /$ month + placebo), $68.5 \%$ in group 3 (golimumab $50 \mathrm{mg} /$ month + methotrexate), and $69.7 \%$ in group 4 (golimumab $100 \mathrm{mg}$ / month + methotrexate). Severe adverse events were reported in $2.3 \%, 3.8 \%, 5.6 \%$ and $9.0 \%$ of patients, respectively (42). No new side effects were observed after 2 years of treatment with golimumab plus methotrexate (44).

A recent study published in Arthritis Care \& Research analyzed the cases of tuberculosis that developed among the 2210 patients treated with golimumab for one year in the five regulatory trials (46). These studies permitted the recruitment of patients with latent tuberculosis at baseline, who had undergone isoniazid prophylaxis one month before starting the study: none of these 317 patients developed active tuberculosis during the 52 weeks of followup. Overall there were 5 cases of active tuberculosis in patients who screened negatively at baseline, all of them in patients from countries with high background rates of disease. An adequate screening program before initiating biologic therapy is very important in that it reduces the incidence of reactivation of latent tuberculosis by up to $85 \%$ (46).

A recent meta-analysis assessed the risk of malignancy in 29,423 RA patients treated with biological agents (including golimumab) in the course of 63 clinical trials of at least 6 months' duration. The use of biological drugs in this setting is not associated with a significantly increased risk of developing a malignancy compared with other active drugs (DMARD) or placebo (47). The meta-analysis by Le Blay et al. focused on the neoplastic risk of certolizumab and golimumab in $2710 \mathrm{RA}$ patients enrolled in randomized clinical trials (48). Among patients treated with anti-TNF agents, 18 cases of malignancy were observed and 9 cases of nonmelanoma skin cancer (NMSC) versus 4 and 3 cases, respectively, in the control group, with an odds ratio of 1.06 for the risk of malignancy and 0.69 for that of NMSC with certolizumab and golimumab versus DMARDs. The results 
of this meta-analysis did not show an increased risk of any type of malignancy, although further data on the long-term use of these anti-TNF agents are required (48).

\section{COMFORT OF ADMINISTRATION}

The usefulness of a treatment in the clinical practice depends not only on efficacy, but also on acceptability and comfort of administration.

Patient comfort with SC injections depends both on the formulation of the solution and the administration of the drug itself. The factors that affect tolerance are the solution volume, the strength and composition of the buffer, reactions at the injection site and the frequency of injections. The L-histidine buffer used in golimumab has proved to be less painful and better tolerated than the citrate buffer solution used in the SC formulations of other anti-TNF agents; moreover histidine buffers are no more painful than saline solution (49). The low injection volume $(0.5 \mathrm{ml}$ per dose $)$ and the composition of golimumab solutions for injection mean that patients experience less pain at the injection site (50).

Golimumab is the first effective single-use anti-TNF agent administered subcutaneously once a month. It comes in two convenient formulations: a pre-filled, singledose syringe or a single-dose SmartJect autoinjector (pre-filled pen containing 0.5 $\mathrm{ml}$ of solution, designed to ensure fast and simple delivery).

The GO-MORE trial also evaluated the use of the autoinjector for the SC administration of golimumab. According to the majority of patients, the autoinjector was easy to use, and caused neither discomfort nor pain. After 6 months, many of the patients assessed for efficacy reported that they preferred to inject into the thigh $(75.2 \%$; $1563 / 2077$ ). Over $95 \%$ of patients considered the use of the autoinjector to be safe/ very safe and $92.1 \%$ were satisfied/very satisfied with the monthly frequency of self-injections. Responses did not change in the different age groups. After 6 months, the experience with the self-injection process was rated as extremely positive and positive by $53.7 \%$ and $39.5 \%$ of patients without disability, respectively, and by $42.5 \%$ and $49.1 \%$ of those with disability (51).

\section{COST OF THERAPY}

RA, AS, and PsA have a high economic impact on the individual and on society. The annual mean total cost of RA per patient in Europe $€ 14,906$, whereas that of AS is $€ 9,374$ (52). The mean total cost (direct plus indirect) of a patient with PsA in Italy is approximately $€ 3.000$ (53). Discontinuation or change in therapy are common occurrences during treatment with anti-TNF- $\alpha$ agents, and generally lead to a significant increase in treatmentrelated costs (54). In Italy, the cost of a single $0.5 \mathrm{ml}(50 \mathrm{mg})$ pack of golimumab ( 1 month of treatment) is $€ 1,723.33$ ( $€$ 973.18 as ex-factory price), corresponding to an annual cost of $€ 11,678.14$. These costs are virtually identical to those of the other treatments currently available for AS (adalimumab, etanercept) or for RA alone (abatacept and tocilizumab) (55). An analysis compared the costs of one year of therapy with four subcutaneously injected treatments: adalimumab, etanercept, certolizumab. and golimumab in patients affected by RA. The costs of the drugs for one year of therapy were comparable ( $\$ 19,812$ for adalimumab, $\$ 21,940$ for certolizumab, \$20,190 for etanercept and $\$ 19,824$ for golimumab) (56). A second analysis that simulated treatment of a cohort of 10,000 patients for 5 years estimated a cost per quality-adjusted life-year (QALY) with golimumab of $\$ 6,904$, that is, equivalent to that of other treatments (range, \$ 6,300 - \$6,600) (57).

The use of golimumab in PsA has also been recently analyzed in a decision analysis model which simulated the clinical and economic outcomes of treatment (58). Cost-effectiveness analysis against palliative care showed that golimumab is as costeffective as the other alternatives taken into 
consideration, whereas probabilistic sensitivity analysis showed that golimumab had $50 \%$ and $89 \%$ probability of being costeffective at willingness-to-pay thresholds of $£ 20,000$ and $£ 30,000$ per QALY (58).

Finally, a cost-effectiveness analysis on patients with severe AS demonstrated that, compared with standard therapy, the benefit (incremental cost-effectiveness ratios - ICER) of golimumab, adalimumab, and etanercept were very similar. In addition, golimumab produced the greatest net cost reduction at a willingness-to-pay threshold of $£ 30,000$ per QALY (59).

\section{CONCLUSIONS}

The many large studies conducted on these populations have demonstrated that the golimumab, especially in combination con methotrexate, is effective in improving the signs and symptoms of the disease and the physical function of the patients, even in the long term. Golimumab is indicated for the treatment of severe-to-moderate active forms of PsA, AS and RA not responding adequately to conventional therapy.

The drug has proved to have a safety profile consistent with that of other anti-TNF agents. The use of golimumab proved to be simple and convenient for the patient, and appears to be acceptable in terms of costeffectiveness.

\section{Acknowledgments}

The authors thank Dr Sara Rossini who provided editorial assistance.

\section{Conflict of interest}

M. Govoni has received speaker fees from Pfizer, Abbvie, Roche, Mundipharma. S.Adami has received speaker fees from Amgen, MSD and Eli-Lilly and honoraria for advisory boards from MSD, Amgen and Pfizer. D. Gatti has received speaker fees from Amgen, Abiogen, Merck and Neopharmed/Gentili. O. Viapiana has received speaker fees from Amgen, Abiogen and Merck. M. Rossini, E. Fracassi, L. Idolazzi and G. Orsolini declare that they have no conflict of interest.

\section{REFERENCES}

1. Lonberg N. Human monoclonal antibodies from transgenic mice. In: Chernajovsky Y, Nissim A (Eds). Therapeutic antibodies. Handbook of Experimental Pharmacology. Berlin Heidelberg: Springer-Verlag 2008.

2. Shealy D, Cai A, Staquet K, et al. Characterization of golimumab, a human monoclonal antibody specific for human tumor necrosis factor alpha. MAbs. 2010; 2: 428-39.

3. Nelson AL, Dhimolea E, Reichert JM. Development trends for human monoclonal antibody therapeutics. Nat Rev Drug Discov. 2010; 9: 767-74.

4. Chovel-Sella A, Karplus R, Sella T, Amital H. Clinical efficacy and adverse effects of golimumab in the treatment of rheumatoid arthritis. Isr Med Assoc J. 2012; 14: 390-4.

5. Kay J, Rahman MU. Golimumab: a novel human anti-TNF-alpha monoclonal antibody for the treatment of rheumatoid arthritis, ankylosing spondylitis, and psoriatic arthritis. Core Evid. 2009; 4: 159-70.

6. Zhou H, Jang H, Fleischmann RM, et al. Pharmacokinetics and safety of golimumab, a fully human anti-TNF-alpha monoclonal antibody, in subjects with rheumatoid arthritis. J Clin Pharmacol. 2007; 47: 383-96.

7. Zhuang Y, Xu Z, Frederick B, et al. Golimumab pharmacokinetics after repeated subcutaneous and intravenous administrations in patients with rheumatoid arthritis and the effect of concomitant methotrexate: an open-label, randomized study. Clin Ther. 2012; 34: 77-90.

8. Simsek I, Yazici Y. Safety and clinical efficacy of golimumab in the treatment of arthritides. Drug Healthc Patient Saf. 2010; 2: 169-80.

9. Xu ZH, Lee H, Vu T, et al. Population pharmacokinetics of golimumab in patients with ankylosing spondylitis: impact of body weight and immunogenicity. Int $\mathrm{J}$ Clin Pharmacol Ther. 2010; 48: 596-607.

10. Ling J, Lyn S, Xu Z, et al. Lack of racial differences in the pharmacokinetics of subcutaneous golimumab in healthy Japanese and Caucasian male subjects. J Clin Pharmacol. 2010; 50: 792-802.

11. Kay J, Matteson EL, Dasgupta B, et al. Golimumab in patients with active rheumatoid arthritis despite treatment with methotrexate: a randomized, double-blind, placebo-controlled, dose-ranging study. Arthritis Rheum. 2008; 58: 964-75.

12. Wagner CL, Visvanathan S, Elashoff M, et al. Markers of inflammation and bone remodelling associated with improvement in clinical response measures in psoriatic arthritis patients treated with golimumab. Ann Rheum Dis. 2013; 72: 83-8.

13. Kirkham BW, Wasko MC, Hsia EC, et al. Effects of golimumab, an anti-tumour necrosis 
factor- $\alpha$ human monoclonal antibody, on lipids and markers of inflammation. Ann Rheum Dis. 2013; 73: 161-9.

14. Gossec L, Smolen JS, Gaujoux-Viala C, et al. European League Against Rheumatism recommendations for the management of psoriatic arthritis with pharmacological therapies. Ann Rheum Dis. 2012; 71: 4-12.

15. Kavanaugh A, McInnes I, Mease P, et al. Golimumab, a new human, tumor necrosis factor alpha antibody, administered every four weeks as a subcutaneous injection in psoriatic arthritis: Twenty-four-week efficacy and safety results of a randomized, placebo-controlled study. Arthritis Rheum. 2009; 60: 976-86.

16. Kavanaugh A, Mease P. Treatment of psoriatic arthritis with tumor necrosis factor inhibitors: longer-term outcomes including enthesitis and dactylitis with golimumab treatment in the Longterm Extension of a Randomized, Placebo-controlled Study (GO-REVEAL). J Rheumatol Suppl. 2012; 89: 90-3.

17. Kavanaugh A, McInnes IB, Mease PJ, et al. Clinical efficacy, radiographic and safety findings through 2 years of golimumab treatment in patients with active psoriatic arthritis: results from a long-term extension of the randomised, placebo-controlled GO-REVEAL study. Ann Rheum Dis. 2013; 72: 1777-85.

18. Kavanaugh A, McInnes IB, Krueger GG, et al. Patient reported outcomes and the association with clinical response in patients with active psoriatic arthritis treated with golimumab: findings through 2 years of the GO-REVEAL trial. Arthritis Care Res (Hoboken). 2013; 65: 1666-73.

19. Kavanaugh A, McInnes IB, Mease P, et al. Clinical efficacy, radiographic and safety findings through 5 years of subcutaneous golimumab treatment in patients with active psoriasic arthritis: results from a long-term extension of a randomized, placebo-controlled trial (the GO-REVEAL study). Ann Rheum Dis. 2014; 73: 1689-94.

20. Braun J, van den Berg R, Baraliakos X, et al. 2010 update of the ASAS/EULAR recommendations for the management of ankylosing spondylitis. Ann Rheum Dis. 2011; 70: 896904.

21. Van der Heijde D, Sieper J, Maksymowych WP, et al. 2010 update of the International ASAS recommendations for the use of antiTNF agents in patients with spondyloarthritis. Annn Rheum Dis. 2011; 70: 905-8.

22. Inman RD, Davis JC Jr, van der Heijde D, et al. Efficacy and safety of golimumab in patients with ankylosing spondylitis: results of a randomized, double-blind, placebo-controlled, phase III trial. Arthritis Rheum. 2008; 58: 3402-12.

23. Deodhar A, Braun J, Inman RD, et al. Golimumab reduces sleep disturbance in patients with active ankylosing spondylitis: results from a randomized, placebo-controlled trial. Arthritis Care Res (Hoboken). 2010; 62: 1266-71.

24. Wagner C, Visvanathan S, Braun J, et al. Serum markers associated with clinical improvement in patients with ankylosing spondylitis treated with golimumab. Ann Rheum Dis. 2012; 71: 674-80.

25. Braun J, Deodhar A, Inman RD, et al. Golimumab administered subcutaneously every 4 weeks in ankylosing spondylitis: 104 week results of the GO-RAISE study. Ann Rheum Dis. 2012; 71: 661-7.

26. Braun J, Baraliakos X, Hermann KG, Deodhar A, van der Heijde D, Inman R, Beutler A, Zhou Y, Xu S, Hsu B. The effect of two golimumab doses on radiographic progression in ankylosing spondylitis: results through 4 years of the GO-RAISE trial. Ann Rheum Dis. 2014; 73 : 1107-13.

27. Deodhar A, Braun J, Inman RD, van der Heijde D, Zhou Y, Xu S, Han C, Hsu B. Golimumab administered subcutaneously every 4 weeks in ankylosing spondylitis: 5-year results of the GO-RAISE study. Ann Rheum Dis. 2014 Nov 11. pii: annrheumdis-2014-205862.

28. Braun J, Baraliakos X, Hermann $\mathrm{KG}$, et al. Golimumab reduces spinal inflammation in ankylosing spondylitis: MRI results of the randomised, placebo-controlled GO-RAISE study. Ann Rheum Dis. 2012; 71: 878-84.

29. Smolen JS, Landewé R, Breedveld FC, et al. EULAR recommendations for the management of rheumatoid arthritis with synthetic and biological disease-modifying antirheumatic drugs: 2013 update. Ann Rheum Dis. 2013; 73: 492-509.

30. Smolen JS, Kay J, Doyle MK, et al. Golimumab in patients with active rheumatoid arthritis after treatment with tumour necrosis factor alpha inhibitors (GO-AFTER study): a multicentre, randomised, double-blind, placebo-controlled, phase III trial. Lancet. 2009; 374: 210-21.

31. Smolen JS, Kay J, Landewé RB, et al. Golimumab in patients with active rheumatoid arthritis who have previous experience with tumour necrosis factor inhibitors: results of a long-term extension of the randomised, double-blind, placebo-controlled GO-AFTER study through week 160. Ann Rheum Dis. 2012; 71: 1671-9.

32. Smolen JS, Kay J, Landewé R, et al. Five year safety and efficacy of golimumab in patients with active rheumatoid arthritis despite previous anti-tumor necrosis factor therapy: final study results of the phase 3, randomized, placebo-controlled GO-AFTER trial. EULAR 2013, Madrid 12-15 June 2013. ABS THU0202.

33. Smolen JS, Kay J, Matteson EL, et al. Insights 
into the efficacy of golimumab in patients with active rheumatoid arthritis despite previous anti-tumour necrosis factor therapy: posthoc analyses from the GO-AFTER study. Ann Rheum Dis. 2014; 73: 1811-18.

34. Combe B, Dasgupta B, Louw I, et al. Efficacy and safety of golimumab as add-on therapy to disease-modifying antirheumatic drugs: results of the GO-MORE study. Ann Rheum Dis. 2014; 73: 1477-86.

35. Combe B, Veale D, Burgos-Vargas R, et al. Comprehensive disease control with golimumab in patients with rheumatoid arthritis. EULAR 2013, Madrid 12-15 June 2013. ABS THU0178.

36. Wollenhaupt J, Alonso-Ruiz A, Spieler W, et al. Efficacy and safety of add-on golimumab treatment in patients with rheumatoid arthritis receiving concomitant methotrexate or leflunomide. EULAR 2013, Madrid 12-15 June 2013. ABS AB0273.

37. Durez P, Pavelka K, Lazaro M, et al. Remission rates during golimumab treatment for rheumatoid arthritis are associated with differences in baseline disease states across geographic regions in the GO-MORE study. EULAR 2013, Madrid 12-15 June 2013. ABS AB0281.

38. Emery P, Fleischmann RM, Moreland LW, et al. Golimumab, a human anti-tumor necrosis factor alpha monoclonal antibody, injected subcutaneously every four weeks in methotrexate-naive patients with active rheumatoid arthritis: twenty-four-week results of a phase III, multicenter, randomized, double-blind, placebo-controlled study of golimumab before methotrexate as first-line therapy for earlyonset rheumatoid arthritis. Arthritis Rheum. 2009;60:2272-83.

39. Emery P, Fleischmann RM, Strusberg I, et al. Five-year safety and efficacy of golimumab in methotrexate-naïve patients with rheumatoid arthritis: final study results of the phase 3, randomized, placebo-controlled GO-BEFORE trial. EULAR 2013, Madrid 12-15 June 2013. ABS FRI0178.

40. Emery P, Fleischmann RM, Hsia EC, et al. Efficacy of golimumab plus methotrexate in methotrexate-naïve patients with severe active rheumatoid arthritis. Clin Rheumatol. 2014; 33: 1239-46.

41. Emery P, Fleischmann R, van der Heijde D, et al. The effects of golimumab on radiographic progression in rheumatoid arthritis. Arthritis Rheum. 2011; 63: 1200-10.

42. Keystone EC, Genovese MC, Klareskog L, et al. Golimumab, a human antibody to tumour necrosis factor-alpha given by monthly subcutaneous injections, in active rheumatoid arthritis despite methotrexate therapy: the GOFORWARD Study. Ann Rheum Dis. 2009; 68: 789-96.
43. Keystone E, Genovese MC, Klareskog L, et al. Golimumab in patients with active rheumatoid arthritis despite methotrexate therapy: 52 week results of the GO-FORWARD study. Ann Rheum Dis. 2010; 69: 1129-35.

44. Keystone EC, Genovese MC, Hall S, et al. Golimumab in patients with active rheumatoid arthritis despite methotrexate therapy: results through 2 years of the GO-FORWARD study extension. J Rheumatol. 2013; 40: 1097-103.

45. Keystone E, Genovese MC, Hall S, et al. Fiveyear safety and efficacy of golimumab in patients with active rheumatoid arthritis despite prior treatment with methotrexate: final study results of the phase 3 , randomized placebocontrolled GO-FORWARD trial. EULAR 2013, Madrid 12-15 June 2013. ABS AB0267.

46. Hsia EC, Cush JJ, Matteson EL, et al. Comprehensive tuberculosis screening program in patients with inflammatory arthritides treated with golimumab, a human anti-tumor necrosis factor antibody, in phase III clinical trials. Arthritis Care Res (Hoboken). 2013; 65: 309-13.

47. Lopez-Olivo MA, Tayar JH, Martinez-Lopez JA, et al. Risk of malignancies in patients with rheumatoid arthritis treated with biologic therapy: a meta-analysis. JAMA. 2012; 308: 898-908.

48. Le Blay P, Mouterde G, Barnetche T, Morel J, Combe B. Short-term risk of total malignancy and nonmelanoma skin cancers with certolizumab and golimumab in patients with rheumatoid arthritis: metaanalysis of randomized controlled trials. J Rheumatol. 2012; 39: 712-5.

49. Laursen T, Hansen B, Fisker S. Pain perception after subcutaneous injections of media containing different buffers. Basic Clin Pharmacol Toxicol. 2006; 98: 218-21.

50. Jørgensen JT, Rømsing J, Rasmussen M, Møller-Sonnergaard J, Vang L, Musaeus L. Pain assessment of subcutaneous injections. Ann Pharmacother. 1996; 30: 729-32.

51. Schulze-Koops H, Giacomelli R, Samborski $\mathrm{W}$, et al. Patient evaluations of autoinjectors for delivery of subcutaneous golimumab for treatment of rheumatoid arthritis. EULAR 2013, Madrid 12-15 June 2013. ABS THU0198.

52. Franke LC, Ament AJ, van de Laar MA, Boonen A, Severens JL. Cost-of-illness of rheumatoid arthritis and ankylosing spondylitis. Clin Exp Rheumatol. 2009; 27: (4 Suppl. 55) S118-23.

53. Olivieri I, de Portu S, Salvarani C, et al. The psoriatic arthritis cost evaluation study: a cost-of-illness study on tumour necrosis factor inhibitors in psoriatic arthritis patients with inadequate response to conventional therapy. Rheumatology (Oxford). 2008; 47: 1664-70.

54. Tang B, Rahman M, Meissner B, Dabbous O1, Thompson HC. Association between switch- 
ing patterns among anti-tumor necrosis factors (anti-TNFs) and the healthcare costs in the treatment of rheumatoid arthritis (Poster). ISPOR 10th Annual European Congress; Dublin, Ireland, October 20-23, 2007.

55. Italian Medicines Agency. http://www.agenziafarmaco.gov.it/it/content/liste-di-trasparenza-e-rimborsabilit\%C3\%A0

56. Carter C, Schmeichel-Mueller C, McKenzie RS, Piech CT. Cost analysis of recently approved and older anti-TNF biologic agents used In rheumatoid arthritis. ISPOR 15th Annual International Meeting, Atlanta, GA, USA May 15-19, 2010. Poster PMS7.

57. Nguyen CM, Bounthavong M, Mendes MA, et al. Cost utility of tumour necrosis factor- $\alpha$ inhibitors for rheumatoid arthritis: an application of Bayesian methods for evidence synthesis in a Markov model. Pharmacoeconomics. 2012; 30: 575-93.

58. Cummins E, Asseburg C, Prasad M, Buchanan J, Punekar YS. Cost effectiveness of golimumab for the treatment of active psoriatic arthritis. Eur J Health Econ. 2012; 13: 801-9.

59. Farrell J, Muszbek N, Sheppard O, Chaudhary M, Naci H, Kachroo S. The long term costeffectiveness of golimumab for the treatment of severe, active ankylosing spondylitis in adults who have responded inadequately to conventional therapy. ISPOR 14th Annual European Congress. Madrid, Spain. November 5-8, 2011. Poster PMS47. 